\title{
Desenvolvimento e potencial de clusters criativos para as cidades médias brasileiras
}

Development and potential of creative clusters for brazilian medium-sized cities

Gabriel B. Vaz de Melo

Universidade Federal de Minas Gerais

Guilherme Leite Paiva

Universidade Federal de Minas Gerais

\begin{abstract}
This study investigates the presence of creative clusters in medium-sized Brazilian cities in 2010, and is based on the strategy proposed by Machado, Simões and Diniz (2013). The analysis of medium-sized cities points to the development of typologies, as well as different patterns of creative agglomerations. Also, when detaching the effects of the big and peripheral cities the analysis becomes more homogeneous, contributing to improve the understanding and knowledge of the creative economy in Brazil. The multivariate method of fuzzy clustering, which allows greater approximation of the results with the reality, was applied to a variety of constructed indicators and several other data provided by the national institutes of IBGE, DATASUS and FINBRA. A set of six clusters were selected from specific characteristics of the sample. We analyzed the results, geographical location, and disposition found for each group, with four presenting a more pronounced pattern.
\end{abstract}

\section{Keywords}

creative cluster; agglomeration externalities; medium-size cities; fuzzy clustering.

JEL Codes Z10; C38; R53.

\section{Resumo}

Este estudo investiga a presença de clusters criativos nos municípios médios brasileiros em 2010 e baseia-se na metodologia de identificação proposta por Machado, Simões e Diniz (2013). A análise das cidades médias evidencia a criação de tipologias e diferenças nos padrões das aglomerações criativas. Ao isolar os efeitos dos grandes centros e das cidades periféricas, contribui-se para melhorar o entendimento e conhecimento da economia criativa no Brasil. O método multivariado de fuzzy cluster, que permite maior aproximação dos resultados com a realidade, foi aplicado a diferentes dados disponibilizados pelo IBGE, DATASUS e FINBRA. A partir de critérios específicos, foram selecionados seis clusters para a amostra. Analisou-se à disposição, localização geográfica e os resultados encontrados para cada cluster, sendo que quatro apresentaram um padrão mais aparente. A produção deste conhecimento é fonte importante para o exame adequado das políticas focadas na economia criativa e seus impactos.

\section{Palavras-chave}

clusters criativos; externalidades aglomerativas; cidades médias; fuzzy cluster.

Códigos JEL Z10; C38; R53. 


\section{Introdução}

Externalidades de aglomeração são efeitos ocasionados pelo agrupamento, principalmente geográfico, de firmas ou estruturas de um mesmo ramo de atividade que, não só beneficiam individualmente as firmas, mas também todo o setor a que ela pertence e, possivelmente, toda a economia, via um conjunto de trabalhadores especializados, transbordamento de conhecimento e aumento da diversidade entre os setores. Essas externalidades podem ser por especialização, diversificação ou mesmo competição. Certamente, a economia criativa não está excluída dos efeitos das economias de aglomeração, e a melhor compreensão deste fenômeno possibilita o aumento do potencial de impacto dessas externalidades por meio de estratégias coerentes.

As políticas urbanas costumam ser caracterizadas por amenidades que seriam quaisquer conjuntos de bens, estruturas ou serviços públicos e privados que geram externalidades positivas para a população ou turistas de uma cidade, tais como sistema de transporte, praças, saneamento básico, hospitais, universidades e baixos índices de criminalidade (Machado; Simões; Diniz, 2013). Nas últimas décadas, a discussão sobre as contribuições da cultura e da economia criativa no desenvolvimento regional incorporou como alternativa às políticas urbanas o investimento também em amenidades culturais - museus, teatros, cinemas, festivais e bibliotecas - cada vez mais utilizadas como indicadores de qualidade de vida e até mesmo como forma de revitalização urbana.

Esses conjuntos acabam criando mercados de transações que geram efeitos colaterais (spillovers) e influenciam não só os custos transacionais, mas também decisões locacionais dos indivíduos e firmas (Clark, 2011). Com inspiração no conceito de cidade criativa proposto por Landry e Bianchini (1995) e Florida (2002), propõe-se que a aglomeração de uma classe criativa exerça um papel de atração de outras pessoas e oportunidades de trabalho, além de inovações que posteriormente contribuiriam para impulsionar um desenvolvimento econômico local e regional. Machado, Simões e Diniz (2013) ressaltam que as cidades criativas são definidas de acordo com a presença de vantagens comparativas em termos de sua produção cultural. À vista disso, a análise de clusters criativos possui o potencial de facilitar a identificação e compreensão de grupos que possuem tais vantagens comparativas na produção de cultura. 
Sendo assim, fundado na discussão sobre os efeitos da aglomeração e das amenidades, a proposta deste artigo é a identificação do potencial e desenvolvimento de clusters criativos das cidades médias brasileiras, discutindo suas tipologias e padrões. O recorte para as cidades médias contribui para melhorar o entendimento e conhecimento da economia criativa no Brasil. Ao isolar os efeitos dos grandes centros e das cidades periféricas, a discussão se torna mais homogênea e as relações intra e entre os clusters se tornam mais evidentes, possibilitando um debate mais robusto.

A produção deste conhecimento é fonte importante para permitir o exame adequado das políticas focadas na economia criativa e seus impactos. É relevante também para as estratégias de complementação, diversificação ou especialização nos conjuntos da economia criativa nas cidades médias brasileiras. Sob tais preceitos, o estudo identifica seis clusters criativos pela técnica de análise fuzzy cluster, utilizando diversos dados secundários.

Além desta introdução, o artigo é organizado em mais cinco seções. $\mathrm{Na}$ próxima seção, discute-se a relação entre os conceitos de economia criativa, amenidades urbanas e políticas culturais. Ainda nesta, apresenta-se uma breve revisão da literatura sobre clusters criativos. Na terceira seção, apresentam-se as bases e fontes de dados utilizadas, assim como considerações importantes sobre o desenho do estudo e as transformações realizadas. Os aspectos metodológicos se encontram na quarta seção. Os resultados e avaliação dos mesmos serão apresentados na quinta seção e, por fim, na sexta, expõem-se as considerações finais.

\section{Economia criativa e políticas culturais}

\subsection{Cidades criativas}

A transição pós-industrial na segunda metade do século $X X$ resultou em novos desafios para as cidades no que se refere à atração de capital humano e financeiro. A sociedade pós-industrial é mais capacitada e diversa, não se restringindo somente ao trabalho agrícola e industrial. Os indivíduos ocupam variados setores - maior participação dos serviços - geram conhecimento, inovação, absorvem novas tecnologias, comunicam-se facilmente e deslocam-se em grande escala. Devido às redes de informação e comunicação, defende-se que ocorrem mais trocas comerciais entre países e regiões, oca- 
sionando uma maior variedade de bens e serviços. Simultaneamente, poucas barreiras de mercado estimulariam a demanda global por produtos e serviços especializados (Storper; Salais, 1997; Scott, 2008; Clark, 2011; Vivant, 2012).

A manutenção da atividade econômica nos centros urbanos obrigou os gestores a pensarem além das políticas econômicas e industriais e refletirem, principalmente, sobre as políticas econômicas urbanas e sociais. Markusen e Gadwa (2010) afirmam que essas políticas afloraram na Europa na década de 1980 via revitalização de áreas centrais e desenvolvimento de comunidades e bairros, mas já eram evocadas nos Estados desde a década de 1960 como principal estratégia de planejamento cultural. Nas últimas décadas, ganham destaque a valorização de espaços públicos, a criação de áreas verdes e, principalmente, o incentivo à vida cultural nas cidades - por exemplo, cafés, restaurantes, centros culturais, museus, cinemas, festivais e espaços cênicos. Segundo Vivant (2012), frente às novas demandas e possibilidades de uma "efervescência criativa" das cidades a partir da economia criativa, cada vez mais, as políticas culturais vêm sendo utilizadas como motor de desenvolvimento econômico, o que Clark (2011), por sua vez, nomeia como "Nova Política Cultural".

Algumas dessas medidas passaram a ser fundamentadas pela teoria da classe criativa proposta por Florida (2002). ${ }^{1}$ Para o autor, essa classe toma decisões de localização de acordo com a oferta de serviços, amenidades e qualidade de vida do local condizentes com seu perfil criativo. Assim, para atrair o capital das "empresas criativas" que demandam tecnologia e inovação, a melhor estratégia seria oferecer incentivos para atrair primeiramente essa classe criativa.

Segundo Storper e Scott (2009), além de Clark (2011) e Florida (2002), Glaeser, Kolko e Saiz (2001) também discutem a questão da cidade criativa e dos trabalhadores qualificados. Eles defendem que principalmente as amenidades urbanas seriam responsáveis pela manutenção e atração de capital humano nas cidades. Em concordância com Florida (2002), para os autores, os trabalhadores se interessariam por variedade de serviços e bens de consumo, clima favorável e serviços públicos de qualidade, tais como transporte, saúde e educação.

Porém, segundo Vivant (2012), o conceito de "cidade criativa" precisa ser reformulado. É necessário pensá-lo além dos indicadores e conceitos de 1 Incluem-se não só artistas propriamente ditos, mas também ocupações envolvidas em outros processos de criação, tais como cientistas, pesquisadores, engenheiros e arquitetos. 
Florida (2002), ${ }^{2}$ das revitalizações e construção de equipamentos culturais. Gestores têm explorado excessivamente e erroneamente as políticas urbanistas e culturais, muitas vezes beneficiando poucos grupos de interesse.

Para que as políticas obtenham ganho de fato, Markusen e Gadwa (2010) defendem que ainda são necessários estudos que esclareçam impactos, identifiquem riscos e custos de oportunidades dessas políticas, visando orientar os governos, ou eles continuarão a desperdiçar oportunidades de desenvolvimento cultural. Segundo as autoras:

To test the role played by cultural industries and occupations in the rate of regional job creation, researchers could develop more sophisticated causal models and test them with multivariate analysis. They can use quasi-experimental models to test the impact of cultural investments and control for other developmental forces, especially in smaller towns (Markusen; Gadwa, 2010, p. 15-16).

Nesse sentido, conforme Vivant (2012), as cidades seriam as localidades mais aptas para o desenvolvimento da economia criativa, mas, sobretudo, as cidades médias, como é demonstrado neste trabalho. Storper e Scott (2009) ressaltam que o crescimento urbano na nova economia das cidades não pode ser reduzido às preferências dos trabalhadores e oferta de amenidades. Deve-se, sim, considerar a "lógica e a dinâmica da atividade econômica, especialmente dos sistemas de produção e de trabalho localmente aglomerados" (p. 165). Pesquisas e evidências relacionadas seriam significativas para os formuladores de políticas.

\subsection{Externalidades aglomerativas}

Os setores culturais reúnem processos de criação, favorecidos pela proximidade geográfica e pela interações dos agentes, nos quais se realizam transações e difusão de ideias, e que têm relação e impacto em diversos locais e grupos de indivíduos (Markusen; Gadwa, 2010; Vivant, 2012). Para Lazzeretti, Boix e Capone (2013), as políticas de desenvolvimento a partir da economia criativa podem usufruir de diversas vantagens devido à existência de externalidades de aglomeração ou "clusterização", dado à influência desse fenômeno no setor. Conforme Machado, Simões e Diniz (2013, p. 100),

2 Chamada de "teoria dos 3T's do desenvolvimento econômico": talento, tecnologia e tolerância. Inclui indicadores como número de pessoas com ensino superior, técnicos, estrangeiros, peso da comunidade homossexual e da boêmia artística (Florida, 2002). 
(...) the main reasons for cluster strategy are based on the concept of "agglomeration economies". In this context, such economies can be translated into cost reduction and/or quality improvements, given the spatial concentration of productive resources. Creative industries are affected by agglomeration economies.

Uma primeira externalidade seria por especialização ou localização, caracterizadas inicialmente por Marshall (1920), obtendo vantagens devido à existência de mercado de trabalho especializado, encadeamento produtivos na forma de trocas intersetoriais e ganhos tecnológicos via efeitos de transbordamentos de conhecimento. De acordo com Storper e Salais (1997), sob a lógica Marshalliana, a especialização possui como vantagem que o trabalhador ou empresa sabem mais do produto ou serviço que ofertam do que saberia um ofertante esporádico.

Outra externalidade de aglomeração que a economia criativa pode gozar é a de diversificação ou urbanização, segundo definição de Jacobs (1969). A externalidade por diversificação pode alimentar a economia criativa pela transferência de conhecimento por meio de mecanismos de cross-fertilization. Caso a economia criativa se beneficie de um mercado consumidor local grande ou capacitado, também é possível que a partir da diversidade de consumos e variedade das atividades possa-se gerar uma rede densa e variada de agentes que promovam o mútuo apoio econômico e social e que favoreça a inovação (Scott, 1997; Lazzeretti; Boix; Capone, 2013). Uma região econômica diversa seria capaz de capturar e criar novas atividades, se transformando e se adaptando melhor diante da dinâmica regional (Kemeny; Storper, 2014).

Diante dessas possibilidades, debates econômicos frequentemente permeiam a discussão sobre se seria vantajoso para uma economia se especializar ou diversificar (Beaudry; Schiffauerova, 2009; Kemeny; Storper, 2014). Beaudry e Schiffauerova avaliam diversas estratégias existentes e apresentam uma síntese, ressaltando sob quais condições e circunstâncias cada uma dessas externalidades são mais prováveis de serem encontradas e, também, mais efetivas. Sugere-se que externalidades de diversificação são, em média, mais relevantes e presentes em análises com maior grau de detalhe industrial e desagregação geográfica. Além disso, a diversificação, ante a especialização, aparenta ser mais relevante como fomentador de crescimento de serviços.

Mesmo as externalidades sendo mais efetivas, defende-se que a economia criativa pode se beneficiar tanto das externalidades por diversificação quanto por especialização, visto que um dos fatos estilizados quanto às aglomerações nas cidades é a sua coexistência (Duranton; Puga, 2000). Se 
consideramos o atual sistema econômico como complexas redes socioeconômicas, várias forças atuam sobre ele e são projetadas no espaço urbano. As cidades seriam, portanto, resultado da economia sobre a urbanização e condição necessária para a reprodução e ressurgência de um novo sistema capitalista cognitivo-cultural. Nesse contexto, as ideias de urbanização e aglomeração aliadas às espacialidades passam a ser extremamente relevantes (Storper, 1997; Scott, 2008).

\subsubsection{Evidências de clusters criativos}

O estudo de clusters criativos ganhou destaque nas últimas décadas, ${ }^{3}$ sendo que a discussão teórica, já mais consolidada, tem expandido suas contribuições e alcançado também o campo empírico. Em Propis et al. (2009), os autores identificam que há um reconhecimento crescente e positivo quanto ao papel da indústria criativa na inovação e desenvolvimento, porém ainda com poucas evidências empíricas dos impactos espaciais da mesma. Os autores propõem preencher parte dessa lacuna, mapeando a indústria criativa no Reino Unido em três estágios, progressivamente aumentando o grau de detalhamento geográfico. Os resultados sugerem Londres e outras grandes cidades como locais fortes da indústria criativa no Reino Unido. Contudo, por meio de análise geográfica mais detalhada, foi possível identificar outros bolsões de atividade criativa que contrapõe a ideia de monopólio da indústria em Londres.

Já Lazzeretti, Boix e Capone (2013) buscam compreender melhor os determinantes que fazem com que a indústria criativa se beneficie da aglomeração, isto é, forme clusters. Cinco hipóteses se destacam na literatura - (i) dotações históricas culturais e adjacências ao poder político; (ii) economias de aglomeração; (iii) diversidade relacionada; (iv) capital humano e (v) a classe criativa segundo Florida (2002). Os resultados do exercício empírico, aplicado para Espanha e Itália, indicam que os determinantes atuam com forças distintas para cada país, sendo que as economias de aglomeração foram cruciais em ambos.

Em outro exercício empírico, Grodach et al. (2014) analisa os padrões dos clusters criativos para os Estados Unidos. Os autores avançam na discussão 3 Além de Markusen e Gadwa (2010), Wu (2005), Pratt (2004), Markusen e Schrock (2006), Stern e Seifert (2010). 
ao propor uma análise com maior detalhamento geográfico e investigando as correlações entre os padrões para diferentes densidades populacionais. Os resultados sugerem que, em geral, as indústrias criativas apresentam padrões heterogêneos tanto entre regiões metropolitanas e seus bairros, como para as diferentes densidades populacionais.

Quanto aos estudos brasileiros, Machado, Simões e Diniz (2013) discutem a relação entre amenidades urbanas e o desenvolvimento de clusters criativos para o Brasil. Os autores propõem identificar o potencial da indústria criativa no território brasileiro e utilizam a técnica de análise de cluster para a construção das tipologias e agrupamentos. ${ }^{4}$ Dessa forma, os autores avaliam o potencial dos municípios em termos de amenidades culturais e observam quais municípios possuem o mesmo padrão.

Este artigo busca contribuir para esta literatura, em especial estendendo o estudo de Machado, Simões e Diniz (2013). A nova proposta de recorte e abordagem metodológica favorece maior compreensão da economia criativa no Brasil e dá suporte para aumentar o potencial desse setor por intermédio de políticas públicas focalizadas. A seguir, apresenta-se as fontes dos dados e, depois, a abordagem metodológica.

\section{Base de dados}

\subsection{Fonte de dados}

O estudo utiliza sete bases de dados de três fontes distintas (Tabela 1). Mais de $80 \%$ dos dados são do IBGE, do censo demográfico de 2010, do Produto Interno Bruto dos Municípios 2010 e da MUNIC 2006. O censo é realizado no Brasil a cada dez anos e compreende uma amostragem complexa de todos os municípios brasileiros e aproximadamente $10 \%$ de toda a população. O FINBRA (Finanças do Brasil), a partir de relatórios do Tesouro Nacional, possui informações de receitas e despesas de cada município brasileiro. Desse material foi coletado o total de despesas realizadas em cultura em cada município.

4 O artigo também faz uso do método de análise discriminante para explorar a robustez dos resultados e encontrar municípios que não foram "otimamente" classificados. Ao utilizar a técnica de fuzzy cluster, admite-se que um município tenha grau de pertencimento em mais de um grupo de classificação, e a análise discriminante não se faz mais necessária (ver seção Metodologia). 
Já a MUNIC contempla anualmente, desde 1999, informações a respeito da gestão pública municipal e, em 2006, apresentou um complemento relacionado à cultura em parceria com o Ministério da Cultura. ${ }^{5}$ Entre elas, por exemplo, a existência e características de órgãos e instrumentos de gestão pública ligados à cultura. Abrange também informações sobre a existência de cursos, escolas, oficinas, grupos, atividades e eventos ligados à cultura no município. E, finalmente, algumas informações sobre meios de comunicação e equipamentos públicos em geral, incluindo quantidade de estabelecimentos culturais como bibliotecas, museus, teatros, centros culturais, cinemas e ginásios.

Tabela 1 Descrição das variáveis para formação dos clusters

\begin{tabular}{|c|c|c|}
\hline Variáveis & Descrição & Fonte \\
\hline $\begin{array}{l}\text { Índice de manifestação } \\
\text { cultural }\end{array}$ & $\begin{array}{r}\text { Existência de manifestações } \\
\text { culturais nos municípios }\end{array}$ & MUNIC 2006 (IBGE, 2007) \\
\hline Quociente locacional & $\begin{array}{l}\text { Indicador de especialização em } \\
\text { determinada atividade ou setor }\end{array}$ & Censo 2010 (IBGE, 2011) \\
\hline Despesa com cultura & $\begin{array}{r}\text { Total da despesa com cultura } \\
\text { (per capita) }\end{array}$ & $\begin{array}{r}\text { Tesouro Nacional } 2010 \\
\text { (BRASIL, 2010b) }\end{array}$ \\
\hline População & População em 2010 & Censo 2010 (IBGE, 2011) \\
\hline Museus & Número de museus & MUNIC 2006 (IBGE, 2007) \\
\hline Bibliotecas & Número de bibliotecas & MUNIC 2006 (IBGE, 2007) \\
\hline Teatros & Número de teatros & MUNIC 2006 (IBGE, 2007) \\
\hline Cinemas & Números de cinemas & MUNIC 2006 (IBGE, 2007) \\
\hline Centros culturais & Número de centros culturais & MUNIC 2006 (IBGE, 2007) \\
\hline Estádios e ginásios & Número de estádios e ginásios & MUNIC 2006 (IBGE, 2007) \\
\hline Internet & $\begin{array}{r}\text { Proporção de domicílios com } \\
\text { internet no município }\end{array}$ & Censo 2010 (IBGE, 2011) \\
\hline Saneamento básico & $\begin{array}{l}\text { Proporção de domicílios com } \\
\text { saneamento básico no município }\end{array}$ & Censo 2010 (IBGE, 2011) \\
\hline IFDM Saúde & $\begin{array}{r}\text { Índice FIRJAN de desenvolvimento } \\
\text { municipal em saúde }\end{array}$ & IFDM 2010 (FIRJAN, 2012) \\
\hline $\begin{array}{l}\text { Índice de } \\
\text { empreendedorismo }\end{array}$ & $\begin{array}{l}\text { Proporção de empreendedores, } \\
\text { de acordo com metodologia proposta } \\
\text { por Ribas (2014), em relação à população } \\
\text { economicamente ativa do município }\end{array}$ & Censo 2010 (IBGE, 2011) \\
\hline
\end{tabular}

(continua)

5 Posteriormente, verificou-se a recém disponibilidade do mesmo Suplemento de Cultura para o ano de 2014. Dessa forma, como trabalho futuro, pretende-se atualizar e comparar os resultados. Este trabalho manteve os dados do Suplemento de 2006 devido às mudanças de variáveis feitas para 2014 e visando comparação com Machado, Simões e Diniz (2013). 
Tabela 1 (continuação)

\begin{tabular}{l|r|r}
\hline Variáveis & Descrição & Fonte \\
\hline Ensino médio & $\begin{array}{r}\text { Proporção de indivíduos acima de 25 } \\
\text { anos que completaram o ensino médio }\end{array}$ & Censo 2010 (IBGE, 2011) \\
\hline Índice de terceirização & $\begin{array}{r}\text { Razão entre o valor adicionado } \\
\text { em serviços e o PIB do município, } \\
\text { ajustado pelo maior PIB da amostra }\end{array}$ & $\begin{array}{r}\text { PIB Municípios 2010 } \\
\text { (IBGE, 2012) }\end{array}$ \\
\hline Taxa de homicídio & $\begin{array}{r}\text { Taxa de homicídio para homens } \\
\text { entre 15 e 29 anos de idade }\end{array}$ & DataSUS 2010 \\
& (BRASIL, 2010a) \\
\hline
\end{tabular}

Fonte: Elaboração dos autores.

Dados relativos a homicídios foram obtidos do Departamento de Informática do Sistema Único de Saúde (DataSUS). A partir disso, foi possível calcular taxas de homicídios municipais para 2010 que representam a razão entre o total de mortes masculinas entre 15 e 29 anos em relação ao total de indivíduos masculinos da mesma idade por 100 mil habitantes. Também foi utilizado o índice FIRJAN (Federação das Indústrias do Estado do Rio de Janeiro) de desenvolvimento municipal referente à saúde. Essas variáveis buscam captar fatores relevantes na organização dos espaços criativos, de segurança e saúde pública, respectivamente (Machado; Simões; Diniz, 2013). ${ }^{6}$

\subsection{Desenho do estudo e seleção da amostra}

Este estudo faz um recorte especial para as cidades médias brasileiras. Como já observado, a seleção para as cidades médias visa proporcionar um estudo mais homogêneo e aprofundado da economia criativa no Brasil. A classificação das cidades médias foi feita essencialmente pelo princípio demográfico, porém, com considerações expansivas. Foram consideradas cidades médias as cidades com população entre 50 e 500 mil habitantes,

6 A escolha das variáveis, fonte dos dados e transformações realizadas foram estabelecidas com a finalidade de permitir uma mínima comparação com o estudo de Machado, Simões e Diniz (2013). Destaca-se, no entanto, que neste estudo foram incluídas outras três variáveis - Índice de Terceirização, Índice de Empreendedorismo e número de teatros - e excluídas outras três utilizadas no estudo citado anteriormente - artigos científicos publicados por município em 2010, Índice Florida (proporção de casais que declararam união conjugal com indivíduos do mesmo sexo) e um Índice de Cultura baseado em Análise de Componentes Principais (ACP). 
totalizando 570 municípios. Além desses municípios, também foram incluídos outros que possuíam menos de 50 mil habitantes, mas que foram classificados pela REGIC/2007 (IBGE, 2008) como regiões de influência, ${ }^{3}$ Centros Sub-Regionais, ou 4A, Centro de Zona A, respectivamente 18 e 104 municípios. $^{7}$

A REGIC/2007 (IBGE, 2008) é uma tipologia de hierarquia e rede urbana criada pelo IBGE de acordo com as regiões de influência das cidades. Ela considera diversas características e relações entre as cidades tais como: presença de equipamentos e serviços no município, estrutura de gestão pública e privada, fluxos de pessoas, mercadorias e serviços. Quanto maior a presença de funções ou a intensidade das relações, maior é a polaridade da cidade e maior é o seu nível de centralidade dentro da rede urbana (Correa, 1994).

O IBGE classifica como cidades médias as cidades com população entre 100 mil e 500 mil habitantes. Não obstante, em virtude do objetivo de identificar possíveis cidades criativas, considerou-se incluir cidades com menos de 100 mil e mais de 50 mil. ${ }^{8}$ Ao considerar cidades médias aquelas classificadas como centros sub-regionais (nível 3) ou centros de zona A (nível 4A), supõe-se que essas localidades, independentemente do tamanho populacional, podem apresentar funções centrais capazes de atrair pessoas, serviços e possuir uma região de influência relativa no seu entorno conforme ressaltado:

De fato, diferenças nos valores obtidos para centros em diferentes regiões não necessariamente implicam distanciamento na hierarquia, pois a avaliação do papel dos centros dá-se em função de sua posição em seu próprio espaço. Assim, centros localizados em regiões menos densamente ocupadas, em termos demográficos ou econômicos, ainda que apresentem indicativos de centralidade mais fracos do que os de centros localizados em outras regiões, podem assumir o mesmo nivel na hierarquia (IBGE, 2008, p. 11).

Castro (2010, p. 110) define a centralidade cultural como "(...) o uso e exploração das potencialidades culturais na/da cidade, com o propósito de transformá-la em um centro regional sazonal ou perene". ${ }^{9}$ Neste estudo

7 Os municípios entre 50 mil a 500 mil habitantes são bem diversos quanto sua classificação Regic, apresentando cidades classificadas desde Regic $2 \mathrm{~A}$ a Regic 5. No entanto, a maioria se encontra nas classificações 3 e 4 .

8 Entre esses possíveis polos regionais e locais estão incluídas as cidades de Ouro Preto (MG) - 70 mil habitantes, São Pedro da Aldeia (RJ) - 87 mil, Paulínia (SP) - 82 mil, Russas (CE) - 70 mil, Coruripe (AL) - 52 mil, Cruz das Almas (BA) - 58 mil, entre outras.

9 Nesse sentido, apesar de não estar classificada como cidade média neste trabalho, Guara- 
foram classificados como cidades médias um total de 692 municípios. $\bigcirc$ com menor população foi o São Felix do Araguaia (Mato Grosso, 11 mil habitantes e Regic 4A) e o de maior Niterói (Rio de Janeiro, 488 mil habitantes e Regic 2). Cruz das Almas (BA) com quase 59 mil habitantes em 2010 e classificação Regic 3B (Centro Sub-Regional B) apresenta uma tradição de festividades juninas, por exemplo, configurando-se como uma eventual centralidade cultural, como afirma Castro (2010, p. 116). Cruz das Almas, portanto, representa apenas um caso dessa abordagem de cidades médias e suas posições na hierarquia urbana. ${ }^{10}$

Quanto às dezessete variáveis utilizadas para a identificação dos clusters (Tabela 1), algumas transformações, ajustes e índices se destacam. $\bigcirc$ Índice de Manifestação Cultural foi construído por análise de correspondência múltipla (ACM) realizada com informações específicas sobre a presença de diversas formas e manifestações culturais do município, são elas: existência ou não de patrimônio tombado (material ou imaterial), cursos e concursos ligados à cultura, festivais, feiras (de artesanato, livros, moda e outras), exposições (de fotografia, artes plásticas, artes visuais e outras), manifestações tradicionais populares, orquestra, banda, coral, associação literária, circo, escola de samba, jornal ou revista impressa local, rádio local, TV comunitária, unidade de ensino superior, lojas (discos, CDs, fitas, DVDs, vídeos), livraria, além de grupos de dança, musical, capoeira, carnaval, desenho e pintura, artes plásticas e visuais e artesanato. ${ }^{11}$

Já o Quociente Locacional (QL) é um indicador bastante utilizado na literatura de economia industrial e regional, e conforme (Crocco et al., 2006, p. 218) ressalta “(...) o OL procura comparar duas estruturas setoriais-espaciais. Este é a razão entre duas estruturas econômicas: no numerador tem-se a 'economia' em estudo e no denominador uma 'economia de referência'”. Logo, o OL foi calculado a partir da definição de ocupações de trabalho ligadas ao setor cultural ou atividades criativas, baseada na classi-

miranga (CE) - 4 mil habitantes em 2010 e classificada como Regic 5 (Centro Local) - é um ótimo exemplo. Localizada numa região serrana de clima ameno e a cerca de 100 quilômetros da capital do estado, Fortaleza, o município organiza anualmente o Festival Nordestino de Teatro (FNT) desde 1993, além de receber milhares de visitantes, principalmente do seu entorno (Lopes; Santana, 2015), e artistas nacionais e internacionais para o Festival de Jazz e Blues que ocorre desde 2000.

10 Destacam-se outros trabalhos: Ramos, Matos e Garcia (2012), Oliveira e Soares (2014), Pereira (2002), Garcia e Nogueira (2008), Ramos (2011), Lopes e Henrique (2010).

11 Ao todo, foram utilizadas vinte e sete variáveis na construção do índice. Para acesso aos dados da ACM, favor entrar em contato com os autores. 
ficação de (Machado; Simões; Diniz, 2013). ${ }^{12}$ A fórmula de cálculo foi feita da seguinte maneira:

$$
Q L_{\text {municipio }}^{\text {criativos }}=\frac{\frac{\text { Ocupados }_{\text {municipio }}^{\text {criatios }}}{\text { Ocupados }_{\text {município }}}}{\frac{\text { Ocupados }_{\text {Brativil }}^{\text {crias }}}{\text { Ocupados }_{\text {Brasil }}}}
$$

A inclusão do Índice de Terceirização (IT) baseia-se na ideia de Lemos (1991) na qual o nível de terceirização de determinado local seria o melhor indicador de sua capacidade de polarização. Tal proposição incorpora as concepções de lugar central e de área de mercado desenvolvidas por Christaller (1966) e Lösch (1954), respectivamente. Como ressaltado por Lemos et al. (2003), à medida que o espaço econômico se organiza no entorno de lugares centrais, ocorre a formação de um sistema de hierarquias urbanas e o desenvolvimento de economias regionais.

O nível de centralidade de um local é geralmente determinado de acordo com a oferta de bens e serviços que este oferece, assim, cidades com maiores populações tendem a possuir maior oferta de serviços, inclusive aqueles mais especializados que não são ofertados nas localidades de seu entorno (níveis de centralidade inferiores). Qualquer função urbana especializada será limitada pelo tamanho de mercado da localidade, de acordo com a demanda dos consumidores, isto é, cidades mais especializadas necessitam de um mercado consumidor maior. Portanto, cidades com maior densidade urbana tendem a se constituir como centros de consumo coletivo, com maiores oportunidades econômicas e potencialidades de atração de pessoas em busca de atividades especializadas (Lemos et al., 2003), incluindo a classe criativa (Florida, 2002; Lorenzen; Andersen, 2009).

O IT ajustado ${ }^{13}$ foi obtido de acordo com metodologia e fórmulas propostas por Lemos (1991) e Lemos et al. (2003):

12 Para acesso à lista das ocupações consideradas criativas e respectivos códigos (CBO/2000), favor entrar em contato com os autores.

13 Alguns municípios, por possuírem setores agrícola e industrial menos expressivos, podem provocar distorções no índice, obtendo um IT muito elevado. Lemos (1991) e Lemos et al. (2003) sugerem o cálculo de um fator de ponderação que considere um PIB como referência. O referencial nesta seleção de cidades médias foi o município de Betim (MG), apresentando o maior PIB a preços correntes em 2010. 


$$
\begin{aligned}
& I T_{\text {municipio }}=\frac{V A_{\text {serviços }}}{P I B_{\text {municipio }}} \\
& V A_{\text {convertido }}=1-e^{\left(\frac{\ln (0.05)}{P I B_{\text {ref }}} \times P I B_{\text {municipio }}\right)} \\
& I T_{\text {ajustado }}=I T \times V A_{\text {convertido }}
\end{aligned}
$$

Em (3.3) um conversor logarítmico de escala atribui um fator 0.95 referencial ao maior PIB observado (Lemos et al., 2003, p. 672), e em (3.4), tanto o numerador quanto o denominador encontram-se a preços correntes e o valor adicionado (VA) de serviços inclui valores referentes à administração, saúde e educação.

A inclusão do índice de empreendedores (Tabela 1) justifica-se por estudos que sugerem uma relevante presença de empreendedores no setor cultural, seja como geradores de inovação, com ou sem fins lucrativos, ou somente por motivações próprias (Blaug; Towse, 2011). ${ }^{14}$ Empreendedores teriam uma relação positiva com a superação da pobreza, seja de determinado indivíduo, domicílio ou de determinada localidade (Verrest, 2013; Ribas, 2014). Sobre os empreendedores criativos defende-se que:

Creative entrepreneurs drive global change, create economic value and promote cultural tradition and innovation. (...) Creative entrepreneurs are found across the creative industries: fashion design, music, film, cuisine and local agriculture, architecture, tourism, museums and cultural centers...wherever culture is thriving creative entrepreneurs are busy building ventures that generate economic opportunity and a diversity of creative and cultural expression (Creative startups, 2014).

A partir disso, foram identificados pelos dados do CENSO/2010 os indivíduos que trabalham por conta própria ou que seriam donos de pequenos empreendimentos (de acordo com o total de empregados). ${ }^{15}$ Além desses indivíduos, a classificação considerou, de acordo com metodologia proposta por Ribas (2014), se o indivíduo estava ocupado no mercado formal ou informal, sua categoria de ocupação e também se era contribuinte de algum instituto de previdência oficial visando distinguir os trabalhadores por conta própria no setor informal, pois estes não seriam considerados 2000; Hurst; Lusardi, 2004). 
empreendedores (Ribas, 2014). A participação dos empreendedores foi calculada em relação à população economicamente ativa.

\section{Metodologia}

A análise de cluster é uma técnica estatística de aglomeração, classificação e exploração multivariada dos dados. O principal objetivo é a agrupamento dos objetos de um conjunto em grupos (clusters) de modo que os objetos pertencentes a um mesmo grupo sejam os mais similares possíveis entre si, além dos mais distintos possíveis dos objetos dos outros grupos. Sendo assim, os clusters são grupos internamente homogêneos e, portanto, a técnica permite a construção de estruturas agregadas e o desenvolvimento analítico de tipologias (Machado; Simões; Diniz, 2013).

O propósito, ao utilizar a análise de cluster, é a construção de uma tipologia das cidades médias brasileiras em termos dos seus atributos culturais. Machado, Simões e Diniz (2013) alertam para as disparidades entre as cidades brasileiras, que não se limitam só à renda e ao desenvolvimento humano, mas também à extensão a qual as cidades acessam as diversas amenidades urbanas. A construção de grupos homogêneos em relação às amenidades culturais possibilitam a melhor compreensão e investigação dessas disparidades.

\subsection{Do cluster ao fuzzy cluster}

$\mathrm{Na}$ literatura de análise de cluster, dois métodos principais se destacam, a saber, o de partição e o hierárquico. $O$ primeiro constrói $k$ clusters sendo que cada um contém ao menos um objeto (n) e cada objeto só pode pertencer a apenas um grupo, isto é, são hard crisp sets. Logo, existem no máximo $k$ clusters. Já os métodos hierárquicos não constroem uma única partição com $\mathrm{k}$ clusters, mas sim um resultado em que lidam com todas as possíveis formas de partição, desde $k=1$ a $k=n$, de uma só vez (Kaufman; Rousseeuw, 1990).

O fuzzy cluster é uma generalização do método de partição. O método fuzzy também constrói $k$ clusters, no entanto, não é mais necessário que cada objeto seja atribuído a um e somente um cluster. O método de fuzzy 
cluster permite que cada objeto tenha seu grau de pertencimento distribuído sobre os diferentes $k$ clusters. Sendo que este grau de pertencimento é denominado de coeficiente de pertencimento e varia em um intervalo entre 0 e $1^{16}$. Logo, o uso do método se justifica por possuir a vantagem de não forçar objetos em classificações específicas e permitir certa ambiguidade dos dados, o que geralmente acontece na prática e é esperado para os clusters criativos devido à complexidade da realidade.

O algoritmo utilizado para a estimação do fuzzy cluster foi o FANNY (fuzzy analysis). Segundo Kaufman e Rousseeuw (1990), o algoritmo FANNY busca minimizar a seguinte função objetivo:

$$
f=\sum_{v=1}^{k} \frac{\sum_{i, j=1}^{n} u_{i v}^{2} u_{j v}^{2} d(i, j)}{2 \sum_{j=1}^{n} u_{j v}^{2}}
$$

onde $d(i, j)$ representa a dissimilaridade entre os objetos $i$ e $j$, além de $u_{i v}$ ser uma pertinência desconhecida do objeto $i$ ao cluster $v$. O valor de $m$ (expoente de pertencimento) precisa ser estritamente maior do que um, sendo que quanto maior o valor mais fuzzy é o resultado. Nota-se que a somatória externa é sobre os $k$ clusters, sugerindo que a função objetivo que se busca minimizar é um tipo de dispersão total. As funções de pertinência estão sujeitas a duas restrições:

$$
\begin{aligned}
& u_{i v} \geq 0 \quad \forall i=1, \ldots, n \text { e } \forall v=1, \ldots, k \\
& \sum_{v=1}^{k} u_{i v}=1 \quad \forall i=1, \ldots, n
\end{aligned}
$$

A primeira restrição implica que o grau de pertinência de um objeto não pode ser negativo, enquanto que a segunda implica que a soma sobre os $k$ clusters precisa ser um. Considerando as restrições, a função objetiva é minimizada numericamente por um algoritmo interativo até que convirja. O coeficiente de partição de Dunn $(F k)$ e sua respectiva versão normalizada $(F k)$ permitem que se analise o quão hard ou fuzzy são os clusters resultantes.

16 A soma dos coeficientes de um mesmo objeto é sempre 1. Além disso, ressalta-se que o coeficiente de pertencimento de um objeto não é interpretado como a probabilidade de o mesmo pertencer a tal cluster e sim o grau que efetivamente pertence (Simões, 2003). Por exemplo, as características culturais de Betim possuem aproximadamente 97,6\% dos atributos requeridos para que seja um representante perfeito do cluster 4 . 


\section{Resultados $^{17}$}

A Tabela 2 apresenta as médias dos clusters, isto é, a média dos municípios que os compõe. Tais médias podem ser interpretadas como os valores das características do objeto representativo dos clusters. Constata-se que o número total de municípios nos clusters é de 752 (Tabela 2). Ou seja, 60 a mais que o total de municípios da amostra, 692. Como destacado na seção 4, o método fuzzy permite identificar não só a vinculação principal (nearest crisp (luster), como também vinculações secundárias de cada município a agrupamentos correlatos (Simões, 2003). Os grupos foram estabelecidos associando os municípios com grau de pertencimento $\left(u_{i v}\right)$ maior que $30 \%$ ao seu respectivo cluster $v$. Isto é, só se considerou um município parte do cluster caso este tivesse $u_{i v} \geq 0,3 .{ }^{18}$

A escolha de $k=6$ foi realizada após exame de três medidas internas de validação de clusters $^{19}$ (connectivity, silhouette width e dunn index) e também da análise do ranking ótimo ${ }^{20}$ dos resultados, que combinam, ao mesmo tempo, as três medidas de validação. Ressalta-se que, além das alternativas supracitadas, optou-se pela distância euclidiana ${ }^{21}$ para a construção da matriz de dissimilaridade e, também, que o valor do expoente de pertencimento $(m)$ fosse de $1,5 .^{22}$

17 Todas as estimativas e resultados apresentados neste e nos outros tópicos foram executados utilizando o software estatístico Stata12 e R versão 3.2.2.

1860 municípios (8,6\% da amostra) apresentaram grau de pertencimento superior a $30 \%$ para mais de um cluster. Justifica-se a escolha do limite inferior igual a 30\% devido ao número de clusters $(k=6)$. Um número maior (menor) de $k$ levaria a escolha de um limite menor (maior).

19 As medidas de validação internas captam a conectividade, separação e densidade dos clusters. A conectividade avalia qual a relação entre os objetos de certo cluster com seus c clusters vizinhos mais próximos. O valor do método de connectivity varia entre zero e infinito, devendo este ser minimizado. Medidas que analisam a homogeneidade (via variância intracluster) são denominadas de medidas de densidade. Já as medidas que avaliam o grau de separação dos clusters são, obviamente, as de separação. Silhouette width e dunn index são métodos populares que combinam as validações de separação e densidade, sendo que ambas as medidas devem ser maximizadas, atingindo o valor máximo em 1 (Brock et al., 2008). Para uma apresentação e descrição completa das medidas de validação, assim como dos algoritmos de estimação, ver Brock et al. (2008).

20 A ordem do número ótimo de $k$, selecionado pelo algoritmo de ranking de agregação desenvolvido por Sekula et al. (2015) foi: $k=2$, 4, 6, 3, 7, 8 5, 9 e 10. Testou-se $k=4$ e k = 6 , sendo a opção pelo maior número de clusters definida em razão do objetivo do estudo de obter maior detalhe quanto às diferentes tipologias.

$21 d(i, j)=\sqrt{\sum_{f=1}^{p}\left(x_{i j}-x_{i f}\right)^{2}}$

22 Esta alternativa se justifica pela estrutura dos dados. A análise das medidas de validação 
Tabela 2 Resultados da formação de fuzzy clusters - média intra-clusters

\begin{tabular}{|c|c|c|c|c|c|c|c|}
\hline Variável/Cluster & $\begin{array}{r}\text { Cluster } \\
1\end{array}$ & $\begin{array}{r}\text { Cluster } \\
2\end{array}$ & $\begin{array}{r}\text { Cluster } \\
3\end{array}$ & $\begin{array}{r}\text { Cluster } \\
4\end{array}$ & $\begin{array}{r}\text { Cluster } \\
5\end{array}$ & $\begin{array}{r}\text { Cluster } \\
6\end{array}$ & Média \\
\hline $\begin{array}{l}\text { Índice de manifesta- } \\
\text { ção cultural }\end{array}$ & 2,90 & 2,58 & 3,17 & 3,84 & 2,49 & 3,35 & 2,91 \\
\hline Quociente locacional & 0,80 & 0,75 & 0,92 & 1,11 & 0,83 & 0,97 & 0,86 \\
\hline $\begin{array}{l}\text { Despesa com cultura } \\
\text { (per capita) }\end{array}$ & 19,70 & 15,20 & 15,71 & 16,04 & 14,55 & 14,44 & 16,2 \\
\hline População & 80.794 & 56.551 & 120.833 & 360.282 & 32.693 & 212.872 & 108.452 \\
\hline Número de museus & 1,06 & 0,75 & 1,09 & 3,24 & 0,72 & 1,72 & 1,16 \\
\hline Número de bibliotecas & 1,63 & 1,56 & 2,12 & 5,80 & 1,59 & 3,38 & 2,14 \\
\hline Número de teatros & 1,12 & 0,91 & 1,69 & 3.71 & 0,70 & 2,15 & 1,42 \\
\hline Número de cinemas & 0,55 & 0,28 & 0,81 & 2,55 & 0,20 & 1,63 & 0,75 \\
\hline $\begin{array}{l}\text { Número de centros } \\
\text { culturais }\end{array}$ & 0,69 & 0,62 & 0,90 & 2,31 & 0,43 & 1,26 & 0,87 \\
\hline $\begin{array}{l}\text { Número de Estádios } \\
\text { e Ginásios }\end{array}$ & 4,66 & 3,27 & 4,99 & 10,67 & 3,76 & 5,91 & 4,78 \\
\hline Acesso à internet & 0,25 & 0,19 & 0,29 & 0,38 & 0,23 & 0,34 & 0,26 \\
\hline Saneamento básico & 0,61 & 0,50 & 0,67 & 0,79 & 0,51 & 0,76 & 0,61 \\
\hline IFDM saúde & 0,72 & 0,67 & 0,76 & 0,79 & 0,70 & 0,78 & 0,72 \\
\hline $\begin{array}{l}\text { Índice de empreende- } \\
\text { dorismo }\end{array}$ & 0,076 & 0,070 & 0,078 & 0,085 & 0,092 & 0,080 & 0,078 \\
\hline Ensino médio & 0,18 & 0,15 & 0,21 & 0,25 & 0,17 & 0,23 & 0,19 \\
\hline $\begin{array}{l}\text { Índice de terceirização } \\
\text { (ajustado) }\end{array}$ & 0,07 & 0,04 & 0,10 & 0,29 & 0,02 & 0,20 & 0,09 \\
\hline $\begin{array}{l}\text { Taxa de homicídio } \\
\text { (por } 100 \text { mil hab.) }\end{array}$ & 93,83 & 69,77 & 115,55 & 134,62 & 45,25 & 134,96 & 89,56 \\
\hline Total de municípios & 163 & 209 & 137 & 51 & 110 & 82 & 692 \\
\hline
\end{tabular}

Fonte: Elaboração dos autores.

Verifica-se pela Tabela $2^{23}$ que a classificação dos municípios aos respectivos clusters parece ter uma relação estreita com o tamanho da população

com mais métodos além do fuzzy sugerem que os dados se ajustam melhor a clusters mais harder e menos fuzzy.

23 Sobre os clusters, os coeficientes Dunn padrão e normalizados foram, respectivamente, 0,80 e 0,76 e indicam um crispier cluster. $O$ valor de ajustamento médio de si em todo o conjunto foi de 0,55 e as respectivas médias de spor cluster, do 1 ao 6 , foram: 0,53; 0,63; 0,42; 0,$50 ; 0,59$ e 0,53 . Silhouette width $\left(s_{i}\right)$ é uma medida de ajustamento dos dados, quanto mais próximo de 1 (-1), melhor (pior) ajustado é o cluster. A média de $s$ do conjunto nada mais é que a média simples de todas as $s_{i}$ para cada objeto $i$. 
do município. Dessa observação, podemos inferir que muitos atributos culturais estão relacionados com a densidade populacional, indicando que quanto maior for a densidade, maior será a quantidade de amenidades culturais disponíveis. É interessante observar como a densidade populacional é tão relevante mesmo quando analisada uma amostra mais homogênea (cidades médias). Uma vez que se espera que uma maior densidade populacional proporcione maior diversidade da base produtiva da cidade, tamanha relevância pode ser evidência de que as externalidades por diversificação tenham papel central na indústria criativa. Esta evidência estaria em linha com a teoria discutida na seção 2. As comparações entre os clusters, em que as distâncias populacionais entre os mesmos são menores, tal como 2 e 5 , se destacam devido à homogeneidade.

Os clusters 4 e 6 são os mais singulares, possuem maior densidade populacional e apresentam os menores agrupamentos de municípios, 51 e 82, respectivamente. Ambos possuem as maiores quantidades de amenidades culturais físicas (museus, bibliotecas, teatros, cinemas, centros culturais, estádios e ginásios), acima da média total, porém, as despesas com cultura se mantêm próximas da média para toda a amostra. Destaca-se, negativamente, a elevada taxa de homicídios, o que pode ter relação com a densidade populacional. Os índices de manifestação cultural, empreendedorismo, terceirização, além da proporção de pessoas com ensino médio completo e de domicílios com acesso à internet são todos acima da média, sempre com o cluster 4 à frente. Em relação à concentração de ocupações criativas, determinada pelo quociente locacional, os dois clusters são os mais concentrados também. $O$ valor referente ao cluster 4 foi maior que 1 , ou seja, concentração acima da média brasileira, enquanto que do cluster 6 foi bem próximo $(0,97)$.

Titulou-se, portanto, o cluster 4 de "Aglomerações muito criativas" e o cluster 6 de "Aglomerações criativas". Exemplos de municípios que compõem o cluster 4 (51 municípios) seriam as capitais de porte médio Boa Vista (RR), Vitória (ES), Rio Branco (AC), Florianópolis (SC), Porto Velho (RO) e Macapá (AP), além de outras cidades com elevada densidade populacional como Betim (MG), Olinda (PE), Santos (SP), São José do Rio Preto (SP), Niterói (RJ), Ananindeua (PA), Belford Roxo (RJ), Caxias do Sul (RS), Vila Velha (ES), Campina Grande (PB), Montes Claros (MG), entre 
outras. ${ }^{24}$ Entre os 51 municípios desse agrupamento, 28 foram classificados pela REGIC, sendo que, destes, 24 são capitais regionais (Regic 2), ou seja, localidades que "têm área de influência de âmbito regional, sendo referidas como destino, para um conjunto de atividades, por grande número de municípios" (IBGE, 2008, p. 11).

Do cluster 6 (82 municípios) destacam-se: as capitais Palmas (TO) e Boa Vista (RR) -novamente - além de Taubaté (SP), Limeira (SP), São José dos Pinhais (PR), Governador Valadares (MG), Suzano (SP), Santa Maria (RS), Volta Redonda (RJ), Foz do Iguaçu (PR), Camaçari (BA), Santa Luzia (MG), Sete Lagoas (MG), Divinópolis (MG), Mossoró (RN), Ipatinga (MG), entre outros, ${ }^{25}$ Dos 82 municípios desse cluster, 39 possuem classificação REGIC/2007 e, diferentemente do cluster 4, observa-se maior presença de centros sub-regionais (Regic 3), somando 14, mas ainda com muitas capitais regionais, que totalizam 25 .

Ainda sobre os resultados apresentados na Tabela 2, ressalta-se a alta despesa com cultura referente ao cluster 1 , mesmo apresentando amenidades culturais correspondentes à sua densidade populacional. Aparentemente, a maior despesa não se reflete em melhor distinção do cluster nas outras características. Além das amenidades, o índice de manifestação cultural também está compatível com a média. Esperar-se-ia que ambas as características fossem impulsionadas pelo maior investimento. Observa-se, entretanto, que o cluster 1 possui como membro Paulínia (SP), a qual abriga o Polo Cinematográfico de Paulínia e também organiza o Festival de Cinema anualmente. Essa cidade possui a maior despesa em cultura (per capita) da amostra de cidades médias, cerca de 644,11 reais, enquanto que a média total é de apenas 16,20 reais, e a segunda maior despesa com cultura é a de São Sebastião (SP), igual a 138,10 reais. Calculando novamente a média de despesa em cultura (per capita), excetuando Paulínia, encontramos um

24 Cascavel (PR), Guarujá (SP), Mogi das Cruzes (SP), Petrolina (PE), Petrópolis (RJ), Uberaba (MG), Ribeirão das Neves (MG), Franca (SP), Pelotas (RS), Caruaru (PE), Jundiaí (SP), Maringá (PR), Serra (ES), etc. Em que as citadas Boa Vista (RR), Cascavel (PR) e Guarujá (SP) possuem graus de pertencimento $u_{i v} \geq 0,3$ para os clusters 4 e 6 , sendo o maior para o agrupamento 4 .

25 Criciúma (SC), Cabo Frio (RJ), Sobral (CE), Presidente Prudente (SP), Marília (SP), Dourados (MS), Novo Hamburgo (RS), Barueri (SP), Juazeiro do Norte (CE), Imperatriz (MA), etc. Neste agrupamento (6) Limeira (SP) e Taubaté (SP) também apresentaram $u_{i v} \geq 0,3$ para o cluster 4. Enquanto Boa Vista (RR), Cascavel (PR) e Guarajá (SP) com maior pertencimento ao cluster 4, também fazem parte do cluster 6 . Além dessas, Ibirité (MG), Água Lindas de Goiás (GO) e Nossa Senhora do Socorro (SE) também pertencem ao agrupamento 6, apesar de terem maior grau de pertencimento ao grupo 3 . 
valor igual a 15,85 para o cluster 1 , mais condizente com as características do grupo. Se considerarmos essa média, nota-se também que o cluster 4 passa a ter a maior despesa em cultura entre todos os clusters. O exemplo de Paulínia impulsionando a média da despesa com cultura referente ao seu cluster alerta para os limites e dificuldades de analisar resultados através das médias, especialmente para o caso brasileiro que apresenta grande disparidade entre suas cidades.

Outro resultado notável refere-se ao cluster 5, o de menor população, apresentar o maior índice de empreendedorismo. Comparado com o vizinho mais próximo em termos populacionais (cluster 2), o cluster 5 , mesmo em desvantagem populacional e de despesa cultural, apresenta diversos indicadores superiores, tais como, quociente locacional, número de bibliotecas e estádios, acesso à internet, ensino médio, IFDM saúde e o já mencionado índice de empreendedorismo. Todos os 110 municípios desse agrupamento possuem classificação REGIC/2007: 2 como centro sub-regional A (Regic 3A), 14 como centro sub-regional B (Regic 3B) e 94 como centro de zona A (Regic 4A). Todas as cidades desse cluster possuem população inferior a 50 mil habitantes (Nova Venância/ES possui aproximadamente 46 mil), logo, supõe-se que elas foram classificadas justamente por serem regiões de importante influência. Portanto, optou-se por nomear o cluster 5 de "Pequenos, mas influentes". Por exemplo, entre as cidades do estado de Minas Gerais nesse grupo destacam-se como centralidades locais Diamantina, Almenara, Carangola, Caxambu e São Lourenço. ${ }^{26}$

Graficamente ${ }^{27}$ (Figura 1), é possível observar a distribuição espacial dos clusters e analisar as principais interseções, divisões e densidades dos mesmos. O cluster 3 apresenta maior número de interseções, ou seja, mais intermediário. Não por acaso é o que possui as características mais próximas da média amostral. O cluster 4 é o menos denso e mais disperso, seguido pelo cluster 6 . Também são os clusters menos sobrepostos. Esta observação sugere que a média superior exibida por ambos pode ser especialmente devida a outliers, como Florianópolis (SC) e Ponta Grossa (PR) para cluster 4 e Volta Redonda (RJ) e Araraquara (SP) para o cluster 6.

26 Do mesmo estado também compõem o cluster 5: Além Paraíba, Araçuaí, Capelinha, Guanhães e Salinas.

27 Os clusters são criados a partir de um conjunto de dados multidimensional (17 dimensões neste estudo). Porém, para visualizarmos os resultados em um gráfico (bidimensional), é preciso escolher duas variáveis. Assim selecionamos as variáveis de acordo com os dois primeiros componentes sobre as variáveis utilizadas para a construção dos clusters. 
Figura 1 Cluster Plot

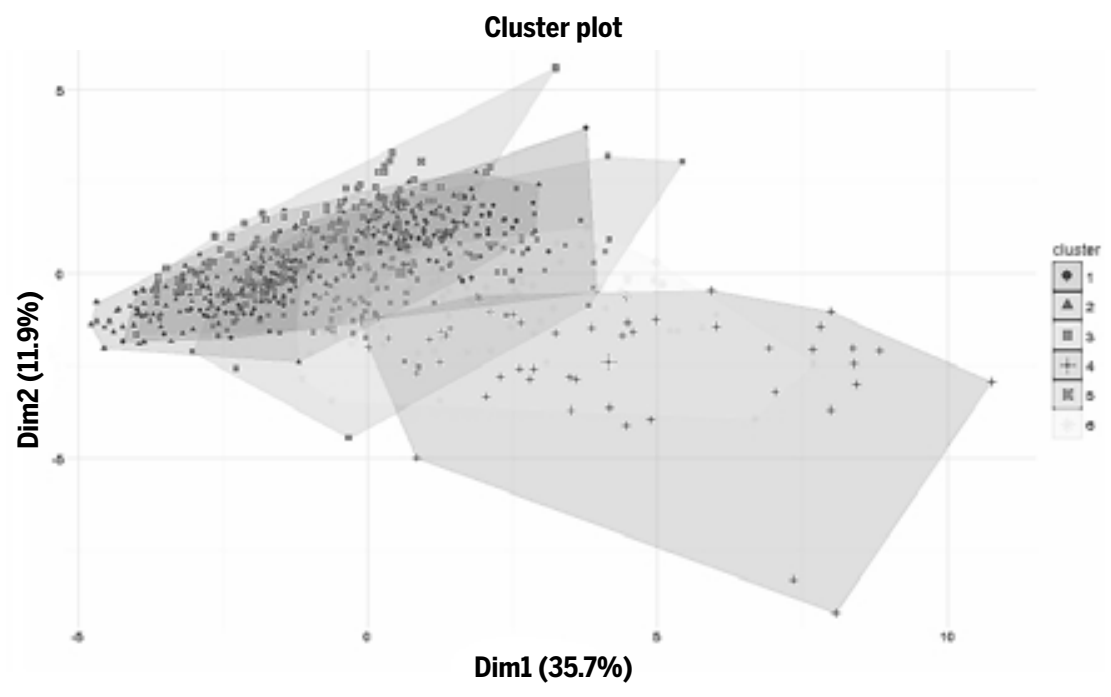

Fonte: Elaboração dos autores.

Os clusters mais distantes são o 4 e 5 , sendo que este último, junto com o cluster 2, são os que apresentam maior e menores quantidades de amenidades culturais, respectivamente. Caracterizou-se o cluster 2, portanto, de "Pequenos e pouco criativos". Os clusters mais densos, compactos, são o 1, 2 e 5, os de menor densidade populacional. Supõe-se que o 2 seja o mais denso de todos, também por ser o de maior agrupamento (209 municípios), apresentando também o melhor ajustamento (Tabela 2). Os três também parecem ser os mais sobrepostos.

A distribuição geográfica, ${ }^{28}$ na Figura 2, assiste no entendimento da formação dos clusters. Todos os clusters possuem ao menos uma cidade média em todas as grandes regiões do Brasil. Ainda assim, é possível observar, visualmente, alguns padrões. Em primeiro lugar, é notório que as cidades médias brasileiras (segundo critério utilizado neste trabalho) estão concentradas nas regiões Sul e Sudeste, ou mesmo no litoral do Nordeste, enquanto que no interior do país são poucos representantes.

28 Neste caso, são apresentados os municípios de acordo com o cluster com maior grau de pertencimento (uiv). 
Figura 2 Distribuição geográfica dos nearest crisp clusters

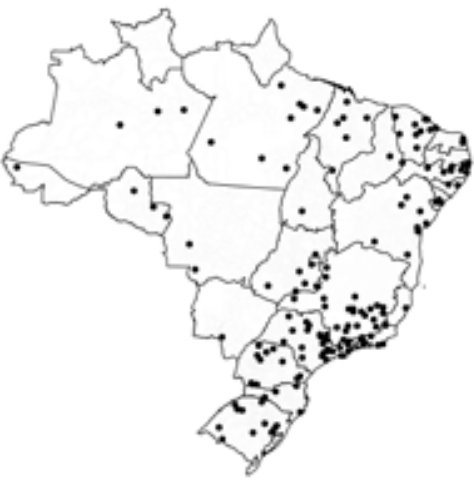

(a) Cluster 1

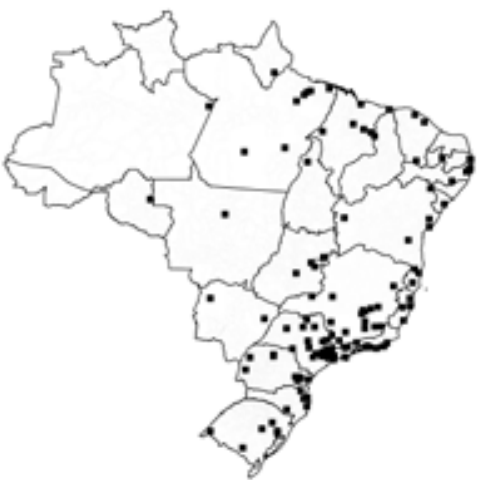

(c) Cluster 3

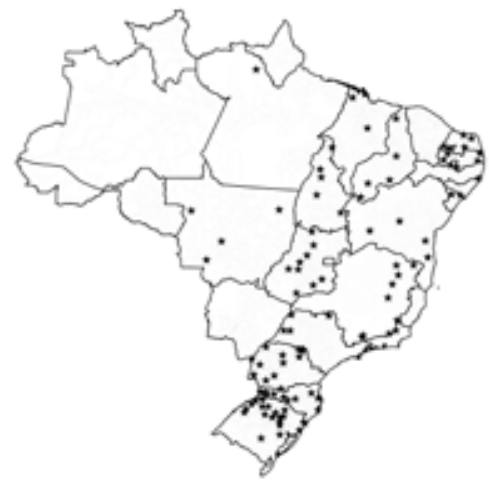

(e) Cluster 5 "Pequenos, mas influentes"

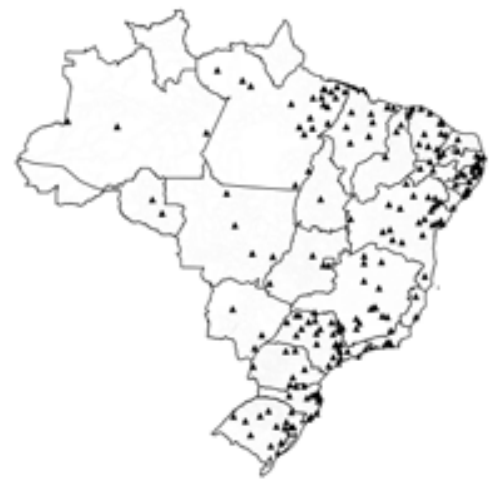

(b) Cluster 2 "Pequenos e pouco criativos"

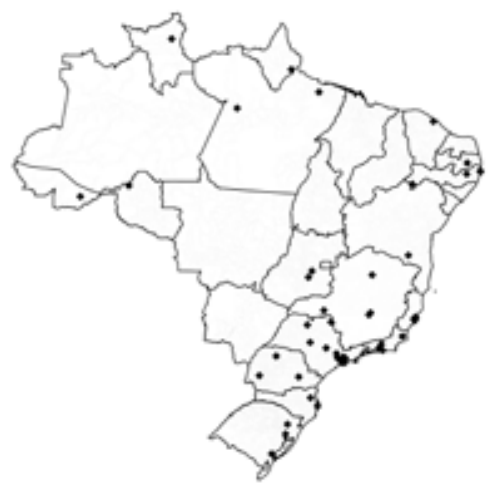

(d) Cluster 4 "Aglomerações muito criativas"

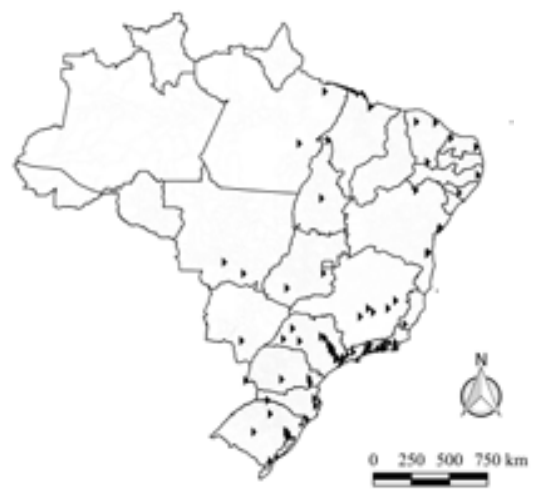

(f) Cluster 6 "Aglomerações criativas"

Fonte: Elaboração dos autores. 
Os clusters 4 ("Aglomerações muito criativas") e 6 ("Aglomerações criativas") concentram se na região Sudeste, principalmente nos estados de São Paulo e Rio de Janeiro. O cluster 5 ("Pequenos, mas influentes") possui forte concentração na região Sul, com alguma relevância também ao redor de Brasília e no Nordeste. Já o cluster 2 ("Pequenos e pouco criativos"), também com baixa densidade populacional, concentra-se nas regiões Norte e Nordeste. Por fim, os clusters 1 e 3 possuem uma localização bem distribuída, dispersa e sem distinção clara de padrão. Tal resultado não causa estranheza, uma vez que estes clusters são os menos peculiares e mais próximos da média amostral.

\section{Considerações finais}

Ao propor um estudo empírico do potencial dos clusters criativos para as cidades médias brasileiras, este artigo busca avançar na análise empírica e espacial da economia criativa no mesmo nível da construção teórica, que se encontra mais avançada. Analisa-se a distribuição espacial das tipologias identificadas, assim como reflexões quanto as interseções e sobreposições das mesmas. Este último ponto é possível devido à escolha metodológica para a construção dos clusters, outro ponto alternativo do estudo. $\bigcirc$ uso da análise de fuzzy cluster permite que os municípios analisados tenham grau de pertencimento em mais de um cluster, aproximando o exercício empírico da realidade. Portanto, não se força as classificações e permite ambiguidade, sendo que aproximadamente $10 \%$ da amostra apresentou classificações mistas.

Como sugerido em Grodach et al. (2014), a indústria criativa apresenta padrões distintos para cada região e até mesmo entre cada recorte geográfico analisado. Logo, é necessário que as políticas e iniciativas sejam focadas nas especificidades das localidades ao invés de esforços generalistas federais e regionais. Este estudo busca contribuir para que seja possível dar mais suporte às iniciativas focadas.

Ressalta-se como resultado os 110 municípios classificados como "pequenos, mas influentes" (cluster 5) que, apesar de ser o agrupamento de menor densidade populacional, foram classificados como cidades médias devido às dimensões de suas regiões de influência. Muitos deles estão situados no interior dos estados das regiões Sul e Nordeste. Devido ao 
menor porte, esses municípios apresentam várias características inferiores se comparadas aos outros clusters (Tabela 2). Porém, apresentam a maior proporção de empreendedores e a menor taxa de homicídios. Estudos de caso específicos acerca desses municípios poderiam originar planos e políticas de desenvolvimento focado nos empreendedores locais e dos arredores. Uma possível política pública poderia abranger, por exemplo, cursos de capacitação para empreendedores culturais que serviriam não só para formação técnica dos habitantes, mas geraria renda extra, oportunidades de serviços para as localidades e expansão da influência em seus entornos. Outra possível medida seria o fortalecimento do sistema de microfinanças e linhas especiais de crédito, que facilitariam a superação de desigualdades sociais e regionais (Verrest, 2013; Ribas, 2014).

A opção pelo desenvolvimento a partir da economia criativa congrega medidas além da revitalização de ambientes físicos e da promoção do ambiente de diversidade nas cidades. Muito menos se compactua com práticas perversas e ultrapassadas de clientelismo e privilégios (Clark, 2011). Além das falhas analíticas em relação às cidades criativas, Scott (2008, p. 82) afirma que:

(...) an odd reticence can be detected in many of the associated policy claims that have been advanced about the possibilities for revival of the social life and physical environment of cities by tapping into the expansionary powers of the cognitive-cultural economy. While it is certainly correct to suggest that cognitive-cultural forms of production and work offer new and dynamic possibilities for urban regeneration, it bears repeating that there is a dark side to the developmental dialectic of contemporary cities, and that the currently deepening trend to neoliberalism in basic economic and political arrangements is actually exacerbating the problem.

Para o autor, uma economia cognitiva-cultural vigorosa perpassa, no mínimo, por um constante debate público e análise das consequências políticas. Assim, inúmeras variáveis devem ser analisadas, tais como criação de oportunidades, redução de desigualdades, segurança, transporte, saúde e educação.

As hipóteses determinantes dos clusters criativos apontadas por Lazzeretti, Boix e Capone (2013) e os seus possíveis ganhos de formação facilitam as relações econômicas, a transmissão de informações, as oportunidades sociais, a estabilidade política e até a resolução de conflitos. Ainda sob essa ótica dos autores, estudos de casos específicos quanto à economia criativa nas cidades médias devem permitir a evolução da compreensão dos mecanismos pelos quais tal opção contribui para a inovação e performance regional. 
Finalmente, outro ponto interessante seria estender o estudo realizando diferentes análises em diferentes estágios geográficos e para períodos mais recentes (conforme disponibilidade da MUNIC 2014), assim como verificar a correlação entre os subsetores das indústrias criativas, como em Propis et al. (2009). Por meio de técnicas de correlação, seria possível explorar os diferentes padrões das tipologias encontradas. Tais extensões, além de mitigar as limitações da análise de médias, permitiriam assimilar quais são os distintos transbordamentos e mecanismos produzidos pela natureza da atividade criativa, assim como suas conexões internas.

\section{Referências}

ACHESON, K.; MAULE, C. J.; FILLEUL, E. Cultural entrepreneurship and the Banff television festival. Journal of Cultural Economics, v. 20, n. 4, p. 321-339, 1996.

BEAUDRY, C.; SCHIFFAUEROVA, A. Who's right, Marshall or Jacobs? The localization versus urbanization debate. Research Policy, v. 38, p. 318-337, 2009.

BLANCHFLOWER, D. G. Self-employment in OECD countries. Labour Economics, Elsevier, v. 7, n. 5, p. 471-505, 2000.

BLAUG, M.; TOWSE, R. Cultural entrepreneurship. In: TOWSE (Ed.). A Handbook of Cultural Economics. Cheltenham, UK: Edward Elgar, 2011. cap. 22.

BRASIL. Ministério da Saúde. Portal do DataSUS. 2010a. Disponível em: <http://www2.datasus.gov.br/DATASUS/index.php?area=02>. Acesso em: 10 de maio de 2017.

BRASIL. STN - Secretaria do Tesouro Nacional. Sistema de Informações Contábeis e Fiscais do Setor Público Brasileiro (Siconfi). Finanças do Brasil 2010 - Dados Contábeis dos Municípios. Brasília, 2010b. Disponível em: <http://www.tesouro.fazenda.gov.br/pt_PT/contas-anuais >. Acesso em: 10 de maio de 2017.

BROCK, G.; PIHUR, V.; DATTA, S.; DATTA, S. cIValid: An R Package for Cluster Validation. Journal of Statistical Software, v. 25, n. 4, p. 1-22, mar. 2008.

CASTRO, J. R. B. A proposição do conceito de centralidade cultural e a promoção de eventos festivos como estratégia de turistificação de pequenas cidades: reflexões a partir de alguns estudos de caso. In: LOPES, D. M. F. L.; HENRIQUE, W. (Ed.). Cidades médias e pequenas: teorias, conceitos estudos de caso. Salvador: SEI, 2010.

CHRISTALLER, W. Central places in Southern Germany. Nova Jersey: Prentice-Hall, 1966.

CLARK, T. N. The City as an Entertainment Machine. Londres: Elsevier, 2011.

CORREA, R. L. A Rede Urbana. São Paulo: Editora Ática, 1994.

CREATIVE STARTUPS. 2014. Disponível em: <http://creativestartups.org/building-creative-economies>. Acesso em: 28 de fev. de 2016.

CROCCO, M. A. et al. Metodologia de identificação de aglomerações produtivas locais. 
Nova Economia, SciELO Brasil, v. 16, n. 2, p. 211-241, 2006.

DURANTON, G.; PUGA D. Diversity and specialization in cities why, where and when does it matter? Urban Studies, v. 37, n. 3, p. 533-555, 2000.

FLORIDA, R. The Rise of Creative Class. Nova Iorque: Basic Books, 2002.

GARCIA, R. A.; NOGUEIRA, M. A inserção das cidades médias mineiras na rede urbana de Minas Gerais. In: XIII SEMINÁRIO SOBRE A ECONOMIA MINEIRA, 2008, Diamantina. Anais... Belo Horizonte: CEDEPLAR, 2008.

GLAESER, E. L.; KOLKO, J.; SAIZ, A. Consumer City. Journal of Economic Geography, p. 27-50, 2001.

GRODACH, C.; CURRID-HALKETT, E.; FOSTER, N.; MURDOCH III, J.The location patterns of artistic clusters: A metro- and neighborhood-level analysis. Urban Studies, v. 51, n. 13, p. 2822-2843, 2014.

HURST, E.; LUSARDI, A. Liquidity constraints, household wealth, and entrepreneurship. Journal of Political Economy, v. 112, n. 2, p. 319-347, 2004.

IBGE. Censo Demográfico 2010. Rio de Janeiro, 2011. Disponível em: <http://www.ibge.gov. br/home/estatistica/populacao/censo2010/default.shtm>. Acesso em: 10 de mai. 2017.

IBGE. Perfil dos Municípios Brasileiros - Pesquisa de Informações Básicas Municipais: Cultura 2006. Rio de Janeiro, 2007. Disponível em: <http://www.ibge.gov.br/home/estatistica/economia/perfilmunic/cultura2006/default.shtm>. Acesso em: 10 de mai. 2017.

IBGE. Produto Interno Bruto dos Municípios 2010. Rio de Janeiro, 2012. Disponível em: $<$ http:// www.ibge.gov.br/home/estatistica/economia/pibmunicipios/2010/>. Acesso em: 10 de mai. 2017.

IBGE. Região de Influência das Cidades 2007. Rio de Janeiro, 2008. Disponível em: <http:// www.ibge.gov.br/home/geociencias/geografia/regic.shtm?c=7>. Acesso em: 10 de mai. 2017.

FIRJAN. IFDM - Índice FIRJAN de Desenvolvimento Municipal 2010. Rio de Janeiro, 2012. Disponível em: <http://www.firjan.com.br/ifdm/downloads/>. Acesso em: 10 de mai. 2017.

JACOBS, J. The Economy of Cities. Londres: Cape, 1969.

KAUFMAN, L.; ROUSSEEUW, P. J. Finding groups in data: an introduction to cluster analysis. Nova Iorque: Wiley, 1990.

KEMENY, T., STORPER, M. Is Specialization Good for Regional Economic Development? Regional Studies, p. 1-16, 2014.

LANDRY, C.; BIANCHINI, F. The Creative City. Londres: Demos, 1995.

LAZZERETTI, L.; BOIX, R.; CAPONE, F. Why do creative industries cluster? In: LAZZERETTI, L. (Ed.) Creative Industries and Innovation in Europe: concepts, measures and comparative case studies. Nova Iorque: Routledge, p. 45-64, 2013.

LEMOS, M. B. Duas técnicas de análise regional elaboradas a partir de categorias espaciais: a regionalização e o método estrutural-diferencial. Tese de Professor Titular, Departamento de Ciências Econômicas, Universidade Federal de Minas Gerais, Belo Horizonte, 1991.

LEMOS, M. B. et al. A nova configuração regional brasileira e sua geografia econômica. Estudos Econômicos, v. 33, n. 4, p. 665-700, 2003. 
LOPES, D. M. F. L.; HENRIQUE, W. Cidades médias e pequenas: teorias, conceitos e estudos de caso. Série estudos e pesquisas, 87. Salvador: SEI, 2010.

LOPES, N. d. N.; SANTANA, A. N. C. O urbano e o rural na (re)produção do espaço em Guaramiranga/CE. Revista da Casa da Geografia de Sobral, v. 17, n. 1, p. 178-188, 2015.

LORENZEN, M.; ANDERSEN, K. V. Centrality and creativity: does Richard Florida's creative class offer new insights into urban hierarchy? Economic Geography, v. 85, n. 4, p. 363-390, 2009.

LÖSCH, A. Economics of Location. Yale University Press, 1954.

MACHADO, A. F.; SIMÕES, R. F.; DINIZ, S. C. Urban amenities and the development of creative clustter: the case of Brazil. Current Urban Studies, v. 1, n. 4, p. 92-101, 2013.

MARKUSEN, A.; GADWA, A. Arts and culture in urban or regional planning: a review and research agenda. Journal of Planning Education and Research, v. 29, n. 3, p. 379-391, 2010.

MARKUSEN, A.; SCHROCK, G. The Artistic Dividend: urban artistic specialization and economic development implications. Urban Studies, v. 43, n. 10, p. 1661-1686, 2006.

MARSHALL, A. Principles of Economics. Londres: MacMillan, 1920.

OLIVEIRA, H. C. M.; SOARES, B. R. Cidade média: apontamentos metodológicos e tipologia. Caminhos de Geografia, v. 15, n. 52, 2014.

PEREIRA, F. M. Cidades médias brasileiras: uma tipologia a partir de suas (des) economias de aglomeração. Dissertação (Mestrado em Economia) - Centro de Desenvolvimento e Planejamento Regional, Universidade Federal de Minas Gerais, Belo Horizonte, 2002.

PRATT, A. Creative clusters: Towards the governance of the creative industries production system? Media International Australia, v. 112, n. 1, p. 50-66, 2004.

PROPIS, L.; CHAPAIN, C,; COOKE, P.; MACNEILL, S.; MATEOS-GARCIA, J. The Geography of Creativity. National Endowment for Science, Technology and the Arts: Interim Report, 2009.

RAMOS, E. F. As cidades médias em perspectiva: uma análise dos papéis e tendências de um grupo de cidades médias brasileiras. Dissertação (Mestrado em Geografia) - IGC, UFMG, Belo Horizonte, 2011.

RAMOS, E. F.; MATOS, R. E. da S.; GARCIA, R. A. As cidades médias como nódulos de equilíbrio da rede de cidades. Revista Paranaense de Desenvolvimento, n. 121, p. 41-63, 2012.

RIBAS, R. Direct and Indirect Effects of Cash Transfers on Entrepreneurship. In: AAEA ANNUAL MEETING, Minneapolis, 2014. Anais... Agricultural \& Applied Economics Association, 2014.

SCOTT, A. J. Social economy of the metropolis: cognitive-cultural capitalism and the global resurgence of cities. Oxford: Oxford University Press, 2008.

SCOTT, A. J. The Cultural Economy of Cities. International Journal of Urban and Regional Research, v. 21, n. 2, p. 323-339, 1997.

SEKULA, M.; DATTA, S.; DATTA, S. optCluster: Determine Optimal Clustering Algorithm and Number of Clusters. R package version 1.0.1., 2015.

SIMÕES, R. F. Localização industrial e relações intersetoriais: uma análise de fuzzy cluster para Minas Gerais. Tese (Doutorado em Economia) - Instituto de Economia, Unicamp, 
Campinas, 2003.

STERN, M. J.; SEIFERT, S. C. Cultural clusters: The implications of cultural assets agglomeration for neighborhood revitalization. Journal of Planning Education and Research, SAGE Publications, 2010.

STORPER, M.; SALAIS, R. Worlds of production: the action frameworks of the economy. Cambridge: Harvard University Press, 1997.

STORPER, M.; SCOTT, A. J. Rethinking human capital, creativity and urban growth.

Journal of Economic Geography, v. 9 (2), p. 147-167, 2009.

SWEDBERG, $R$. The cultural entrepreneur and the creative industries: beginning in vienna. Journal of Cultural Economics, v. 30, n. 4, p. 243-261, 2006.

VERREST, H. Rethinking micro entrepreneurship and business development programs: vulnerability and ambition in low-income urban Caribbean households. World Development, v. 47, p. 58-70, 2013.

VIVANT, E. O que é uma cidade criativa? São Paulo: Editora Senac São Paulo, 2012.

WU, W. Dynamic cities and creative clusters. World Bank Policy Research Working Paper, 3509, 2005.

\section{Sobre os autores}

Gabriel B.Vazde Melo-gabrielvaz@cedeplar.ufmg.br

CEDEPLAR, Universidade Federal de Minas Gerais, Belo Horizonte, Minas Gerais.

Guilherme LeitePaiva-glpaiva@cedeplar.ufmg.br

CEDEPLAR, Universidade Federal de Minas Gerais, Belo Horizonte, Minas Gerais.

Os autores agradecem as contribuições feitas, principalmente, por Rodrigo Ferreira Simões (in memoriam), além de Ana Flávia Machado, Rafael Perez Ribas, Cassiano Ricardo Dalberto e os comentários e sugestões do(a) parecerista.

\section{Sobre 0 artigo}

Recebido em 02 de março de 2017. Aprovado em 26 de maio de 2017. 